\title{
Synthesis of titanium dioxide precursor by the hydrolysis of titanium oxychloride solution
}

\author{
Le Bideau, P..$^{\text {a }}$; Richard-Plouet, M. ${ }^{\text {b }}$; Glouannec, P. ${ }^{\text {; }}$ Magueresse, A. ${ }^{\text {a }}$;ya-Sou, D..$^{\text {; }}$ \\ Brohan, L. \\ ${ }^{a}$ Univ. Bretagne Sud, IRDL, UMR CNRS 6027, F-56100, Lorient, France \\ b Institut des Matériaux Jean Rouxel (IMN), Université de Nantes, CNRS, F-44322, Nantes, France \\ *E-mail of the corresponding author: pascal.le-bideau@univ-ubs.fr
}

\begin{abstract}
This communication focuses on the development of an approach to improve the synthesis of [Ti8O12(H2O)24]Cl8.HCl.7H2O crystals which is one of the precursor for titanium dioxide TiO2 particles. This study provides a significant improvement in crystallization kinetics with a production rate increased by a factor nineteen by intensifying heat and mass transfers compared to the process in a close vessel. This enhancement was made possible by the development of a new reactor to control the heat and mass transfers involved. In parallel with the experimental set-up, a numerical model representative of the transfer phenomena was initiated. The first numerical results are encouraging and present a good agreement with the measurements.
\end{abstract}

Keywords: Heat and mass transfer; Co-desorption, Modelling, Experiment 


\section{Introduction}

Titanium dioxide $\mathrm{TiO}_{2}$ particles are widely used in various applications. Thanks to its high refractive index, the industrial production of $\mathrm{TiO}_{2}$ is mainly dedicated to produce pigments as whitening agent in paints [1]. This transition metal oxide is also well known for its n-type semi-conductivity leading to many applications such as gas sensor [2] or solar cell [3]. Additionnally its bandgap close to $3.2 \mathrm{eV}$ gives interesting properties related to its photoactivity such as photocatalysis, self cleaning, light induced superhydrophilicity, among others. Titanium dioxide can be synthesized from various precursors such as alkoxides or inorganic salts. Depending on the $\mathrm{pH}$, single crystals of $\left[\mathrm{Ti}_{8} \mathrm{O}_{12}\left(\mathrm{H}_{2} \mathrm{O}\right)_{24}\right] \mathrm{Cl}_{8} \cdot \mathrm{HCl} 7 \mathrm{H}_{2} \mathrm{O}$ were demonstrated to selectively lead to different varieties of nanostructured titanium dioxide [4]. The crystals can be obtained by the hydrolysis of titanium oxychloride solution $\mathrm{TiOCl}_{2}, \mathrm{xHCl}, \mathrm{yH}_{2} \mathrm{O}$, called aqueous solution of titanium tetrachloride. Due to the reactivity of the latter with water, it may be difficult to properly ensure the reproductibility of syntheses. Therefore a smart strategy is to use $\left[\mathrm{Ti}_{8} \mathrm{O}_{12}\left(\mathrm{H}_{2} \mathrm{O}\right)_{24}\right] \mathrm{Cl}_{8} . \mathrm{HCl} .7 \mathrm{H}_{2} \mathrm{O}$ as reactant because of the known composition of the crystals and their solubility in polar solvents. With the adequate air temperature and air humidity conditions, the aqueous solution of titanium tetrachloride reacts to produce those crystals in releasing water and hydrochloric acid in the surrounding environment [5]. The formation process of $\left[\mathrm{Ti}_{8} \mathrm{O}_{12}\left(\mathrm{H}_{2} \mathrm{O}\right)_{24}\right] \mathrm{Cl}_{8} \cdot \mathrm{HCl} .7 \mathrm{H}_{2} \mathrm{O}$ is a complex process involving several species and several reaction kinetics. The aim here is to treat mass and heat problems in a highly reactive and deformable medium in order to get insight in the crystallization mechanisms and further optimize the process in order to accelerate the crystallisation. Figure 1 presents a simplified view of the different phenomena involved during the formation of $\left[\mathrm{Ti}_{8} \mathrm{O}_{12}\left(\mathrm{H}_{2} \mathrm{O}\right)_{24}\right] \mathrm{Cl}_{8} \cdot \mathrm{HCl} .7 \mathrm{H}_{2} \mathrm{O}$. The commercial solution is initially composed of 3 species: $\mathrm{TiOCl}_{2}, \mathrm{H}_{2} \mathrm{O}$ and $\mathrm{HCl}$ which react under particular ambient conditions of temperature and humidity to form $\left[\mathrm{Ti}_{8} \mathrm{O}_{12}\left(\mathrm{H}_{2} \mathrm{O}\right)_{24}\right] \mathrm{Cl}_{8} \cdot \mathrm{HCl} .7 \mathrm{H}_{2} \mathrm{O}$. During the process, $\mathrm{TiOCl}_{2}$ and $\mathrm{H}_{2} \mathrm{O}$ species are consumed while $\mathrm{HCl}$ and $\left[\mathrm{Ti}_{8} \mathrm{O}_{12}\left(\mathrm{H}_{2} \mathrm{O}\right)_{24}\right] \mathrm{Cl}_{8} . \mathrm{HCl}_{2} 7 \mathrm{H}_{2} \mathrm{O}$ species are produced. At the solution/air interface, $\mathrm{H}_{2} \mathrm{O}$ and $\mathrm{HCl}$, are transferred to the ambient environment by evaporation. This evaporation causes on the one hand a variation in the volume of the mixture (shrinkage) and on the other hand a modification in the thermal and mass balance leading to temperature and concentration gradients within the mixture.

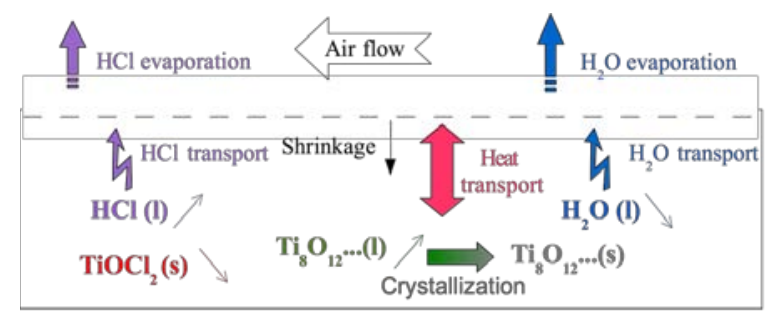

Fig. 1 Schematic description of physical phenomena 
After a brief presentation of the titanium oxychloride solution, the static reactor, the laminar air flow reactor and the metrology used are described. A numerical model predicting the mass behavior of the solution during the first stage of process (before the crystallization kinetic) is presented. The experimental results obtained with the static and dynamic configurations are then discussed and show the capabilities to intensify the crystal production. The first numerical results are finally introduced.

\section{Materials and Methods}

\subsection{Product description}

At ambient temperature $\left(\mathrm{T}=25^{\circ} \mathrm{C}\right)$, titanium oxychloride solution (Cristal) is a viscous, yellow liquid which is highly hygroscopic and very acidic ( $\mathrm{pH}$ far below 1).The titanium oxychloride solution encloses $\left[\mathrm{TiOCl}_{2}\left(\mathrm{H}_{2} \mathrm{O}\right)_{2}\right]$ species dissolved in aqueous hydrochloric solution with the following composition: $1.375 \mathrm{HCl}, 5 \mathrm{H}_{2} \mathrm{O}$. This solution is composed (in percentage by weight) of $54.9 \%$ of the initial species $\left(\mathrm{TiOCl}_{2}\left(\mathrm{H}_{2} \mathrm{O}\right)_{2}\right), 16.1 \%$ of $\mathrm{HCl}$ and 29 $\%$ of water. Based on this composition, the solvent proportion is $64,2 \%$ of water and $35.8 \%$ of $\mathrm{HCl}$. This formulation was validated by placing the commercial solution in an atmosphere containing $36 \% \mathrm{wt} \mathrm{HCl}$ and verifying the mass balance. In classical conditions $\left(\mathrm{T}=25{ }^{\circ} \mathrm{C}\right.$ and $\mathrm{HR} \approx 50 \%$, $\mathrm{HCl}-\mathrm{H}_{2} \mathrm{O}$ co-desorption leads to the crystallisation of $\left[\mathrm{Ti}_{8} \mathrm{O}_{12}\left(\mathrm{H}_{2} \mathrm{O}\right)_{24}\right] \mathrm{Cl}_{8} . \mathrm{HCl} .7 \mathrm{H}_{2} \mathrm{O}$. This crystals formation requires a mass loss of $41.6 \% \mathrm{wt}$ : $15.2 \%$ wt water and $26.4 \%$ wt $\mathrm{HCl}$.

\subsection{Crystallization reactors}

\subsubsection{Static reactor}

The first syntheses were performed in a dessiccator containing a crystallizer filled with $2 \mathrm{~mL}$ of titanium oxychloride solution (solution height approx. $2 \mathrm{~mm}$ ). A $\mathrm{H}_{2} \mathrm{SO}_{4} / \mathrm{H}_{2} \mathrm{O}$ mixture is deposited at the dessiccator base in order to set the relative humidity close to $55 \%$ at ambient temperature. Mass variations and crystals formation are monitored by carrying out discontinuous successive ex situ measurements.

\subsubsection{Laminar air flow reactor}

In order to intensify the massive exchanges and thus the production rate of crystals, a new experimental set-up was developed (Fig. 2). It consists in a rectangular PMMA duct (height: $11 \mathrm{~cm}$, width: $17 \mathrm{~cm})$ in which a PMMA crucible $(10 \mathrm{~cm} \mathrm{x} 10 \mathrm{~cm})$ is placed. Air flow is blown parallel to the surface of the crucible containing the solution. This crucible which contained $22 \mathrm{~mL}$ of titanium oxychloride solution (solution height approx. $2.5 \mathrm{~mm}$ ) is positioned on a weighing system that allows continuous mass monitoring. A heating system stuck below the crucible allowed us to control the solution temperature. The inlet air 
conditions (temperature and relative humidity) are controlled by an upstream system equipped with a heat pump and a humidifier. Temperature sensors placed at upstream, downstream track air temperature variations. Other thermocouples are also stuck on heating element and positioned in the solution. A velocity sensor measures the air speed at the inlet of the duct. All these sensors are connected to a data acquisition system. In the same time, images of the solutions are recorded to track the shrinkage and the crystals formation.

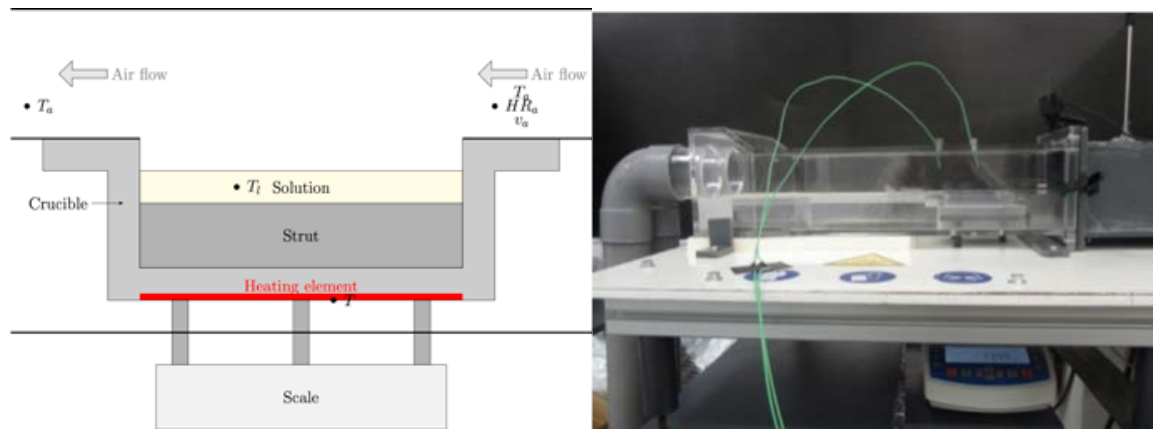

Fig. 2 Laminar air flow reactors description

\subsection{Numerical modeling}

First, a numerical approach is initiated to predict the mass loss of the solution during the first step of the process (before the beginning of the crystallization). This model based on the mass conservation equations written for the solvents $\left(\mathrm{HCl}\right.$ and $\left.\mathrm{H}_{2} \mathrm{O}\right)$ and the solute $\left[\mathrm{TiOCl}_{2}\left(\mathrm{H}_{2} \mathrm{O}\right)_{2}\right]$ should predict solvent concentrations as a function of the surrounding air conditions and/or the temperature of solution imposed by the heating system. The solution temperature is not computed but imposed based on experimental measurements.

The model assumptions are as follows: the initial solution (homogeneous) consists of 3 species $\left[\mathrm{TiOCl}_{2}\left(\mathrm{H}_{2} \mathrm{O}\right)\right]_{2}, \mathrm{H}_{2} \mathrm{O}$ and $\mathrm{HCl}$; the species transport only takes place by diffusion (Fick's diffusion); the species transfer is assumed to be one-dimensional; the shrinkage is assumed to be linear; water reacts with the solute and is consumed to form $\mathrm{HCl}$ species.

\subsubsection{Governing equations}

The application of mass convervation principle leads to write the following equations:

$$
\begin{gathered}
\frac{\partial \rho_{\mathrm{s}}}{\partial \mathrm{t}}+\operatorname{div}\left(\rho_{\mathrm{s}} \overrightarrow{\mathrm{v}_{\mathrm{s}}}\right)=0 \\
\frac{\partial \rho_{\mathrm{i}}}{\partial \mathrm{t}}+\operatorname{div}\left(\rho_{\mathrm{i}} \overrightarrow{\mathrm{v}_{\mathrm{s}}}\right)=-\operatorname{div}\left(\overrightarrow{\mathrm{J}_{\mathrm{l}}}\right)+S_{i}
\end{gathered}
$$

With $\rho$ the mass density $\left(\mathrm{kg} \mathrm{m}^{-3}\right)$, $\mathrm{J}$ the mass flow $\left(\mathrm{kg} \mathrm{m}^{-2} \mathrm{~s}^{-1}\right)$, $\mathrm{S}$ the mass source $\left(\mathrm{kg} \mathrm{m}^{-3} \mathrm{~s}^{-1}\right)$ and $\mathrm{v}$ the shrinkage velocity $\left(\mathrm{m} \mathrm{s}^{-1}\right)$. The subscript i refers to $\mathrm{HCl}$ noted A or water noted W. 


\subsubsection{Boundaries conditions}

At the interface between the solution and the crucible base, no mass transfers occur:

$$
-\mathbf{n}\left(\overrightarrow{J_{1}}\right)=0
$$

At the interface between the solution and the air flow, mass transfers depend on the difference of vapor densities between the product at the surface (surf) and the surrounding air (a):

$$
-\mathbf{n}\left(\overrightarrow{\mathrm{J}_{1}}\right)=\mathrm{h}_{\mathrm{m}}\left(\rho_{\mathrm{i}, \text { surf }}^{\mathrm{v}}-\rho_{\mathrm{i}, \mathrm{a}}^{\mathrm{v}}\right)
$$

With $\mathrm{h}_{\mathrm{m}}$ the mass transfer coefficient $\left(\mathrm{m} \mathrm{s}^{-1}\right)$.

Water vapor and hydrochloric acid vapor are assumed to be ideal gas and the previous relation is expressed as a function of the partial pressure at the product surface and the partial vapor pressure of the ambient atmosphere. Considering that the initial complex does not affect the $\mathrm{HCl} /$ water mixture, it can be assumed that the partial vapor pressures of $\mathrm{HCl} /$ water mixture only depend on the temperature and concentration of $\mathrm{HCl}[6]$.

\section{Results and discussion}

\subsection{Static syntheses}

Various syntheses performed at room temperature and with a relative humidity set at $55 \%$ present similar and repeatable behaviors. In figure 3, a first mass loss is observed during the first hours of drying caused by a significant release of solvents ( $\mathrm{HCl}$ and water). This first stage goes on until the mass loss reaches about $15 \%(\approx 15 \mathrm{~h})$. At this stage, the first crystalline seeds appear and the crystallization kinetic accelerates. Co-desorption is then slowed down as long as the crystals grow and agglomerate. At the end of the process, the mass loss corresponds to about $41 \%$ wt of the initial mass which matches with the predicted value by chemical equations. Under these conditions, about 25 days are required to form the crystals with a production rate per unit surface of about $630 \mathrm{~g} /\left(\right.$ week. $\left.\mathrm{m}^{2}\right)$.

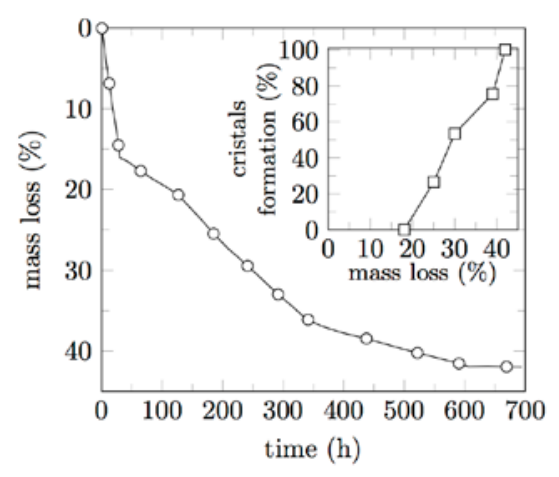

Fig. 3 Mass loss and crystals formation during static syntheses 


\subsection{Dynamic syntheses}

In a second step, syntheses were performed using the laminar airflow reactor. First experiments are carried out without direct heating (Fig. 4). The air temperature $\left(T_{a}\right)$ is set to $28{ }^{\circ} \mathrm{C}$ and relative humidity $\left(H R_{a}\right)$ varies between $45 \%$ and $55 \%$. The air velocity $\left(v_{a}\right)$ is set to about $0.45 \mathrm{~m} \mathrm{~s}^{-1}$.
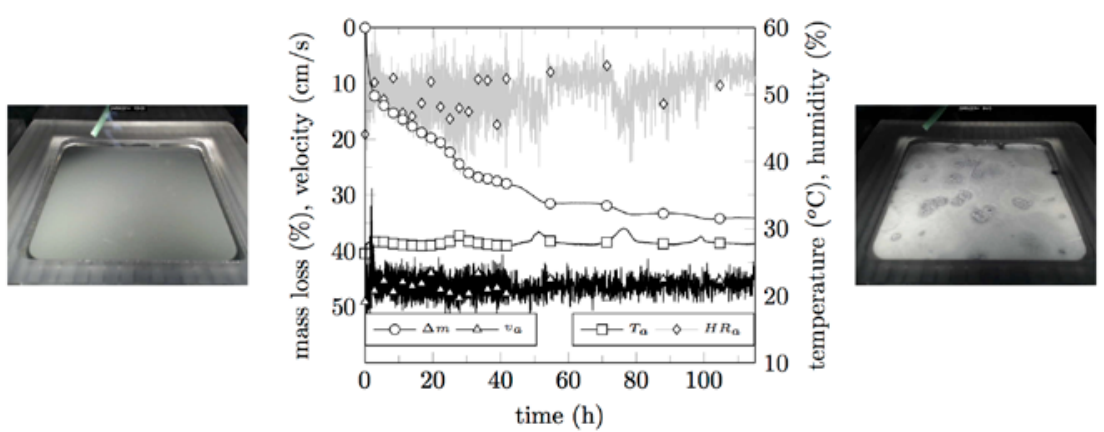

Fig. 4 Dynamic synthesis without direct heating, images of the crucible before (left) and after (right) crystallization, evolution of the mass loss, temperature and relative humidity with time (middle)

In these conditions, the first stage which corresponds to a mass loss $(\Delta m)$ of $15 \%$ is completed in about $8 \mathrm{~h}$. The stationary phase is reached after $110 \mathrm{~h}$ ( $>4$ days). At the end of process, the mass loss corresponds to about $35 \%$ wt and not $41 \%$ as expected. This result can be explained by a crystallization at the surface which prevents the mass diffusion ( $\mathrm{HCl}$ and water) from the medium toward the surface. The production rate of crystals is about 2.2 $\mathrm{kg} /\left(\right.$ week. $\left.\mathrm{m}^{2}\right)$ being more than 3 times the static production rate.

In order to intensify the mass transfer and thus reduce the synthesis time experiments are carried out with a direct heating (Fig. 5). The air temperature $\left(T_{a}\right)$ is set to $27^{\circ} \mathrm{C}$ and relative humidity $\left(H R_{a}\right)$ varies between $50 \%$ and $60 \%$. The air velocity $\left(v_{a}\right)$ is set to $0.45 \mathrm{~m} \mathrm{~s}^{-1}$.

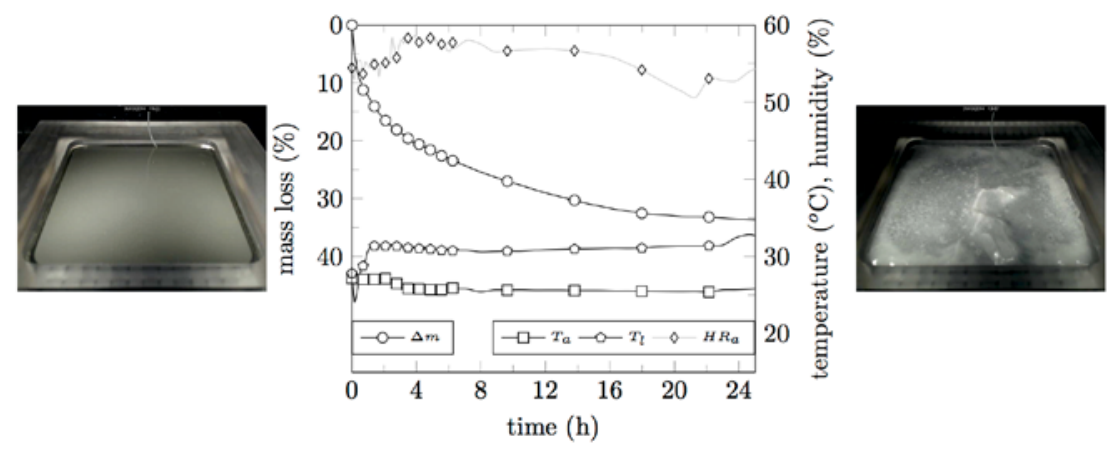

Fig. 5 Dynamic synthesis with direct heating, images of the crucible before (left) and after (right) crystallization, evolution of the mass loss, temperature and relative humidity with time (middle) 
The solution temperature $\left(T_{l}\right)$ varies from $27^{\circ} \mathrm{C}$ to $32^{\circ} \mathrm{C}$ during the first two hours due to switching on of the heating element (heating element temperature about $42^{\circ} \mathrm{C}$ ). The first stage which corresponds to a mass loss of $15 \%$ is completed within about $2 \mathrm{~h}$. The stationary phase is reached after $24 \mathrm{~h}$. At the end of process, the mass loss corresponds to about $34 \% \mathrm{wt}$ which is very similar to the value obtained in the previous case (without heating element). In this condition, the production rate of crystals is about $12 \mathrm{~kg} /\left(\right.$ week.m $\left.{ }^{2}\right)$, i.e., 19 times the production rate achieved in static mode.

\subsection{Numerical results}

The numerical model is tested for the dynamic configuration in the first hours of the synthesis process (before the beginning of the crystallization). The predicted mass losses are compared with the experimental ones for the tests performed without and with direct heating (Fig. 6). For these two configurations, the numerical results present a good agreement with the measurements. Experimentally, the solution density varies from 1.58 at the initial state to 1.5 when the mass loss reaches $20 \%$.

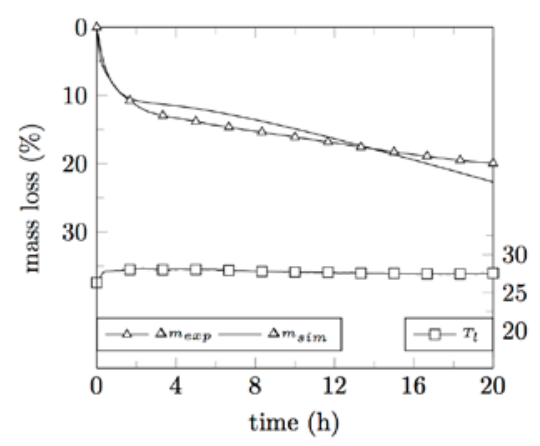

(a)

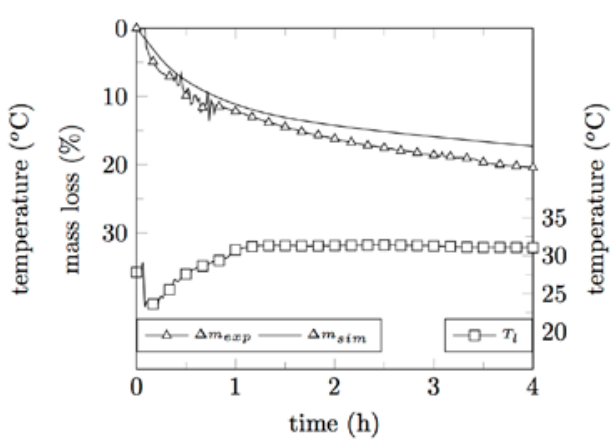

(b)

Fig. 6 Evolution of the temperature (open square), experimental (open triangle) and simulated (line) mass losses without (a) and with (b) direct heating, as a function of time

\section{Conclusions}

Under static conditions, the production of $\left[\mathrm{Ti}_{8} \mathrm{O}_{12}\left(\mathrm{H}_{2} \mathrm{O}\right)_{24}\right] \mathrm{Cl}_{8} \cdot \mathrm{HCl} .7 \mathrm{H}_{2} \mathrm{O}$ crystals requires several weeks. In order to improve the production rate, a laminar air flow reactor with temperature and humidity controls was developed. With adequate conditions (air and solution temperature and air relative humidity), a significant improvement in the crystals production was obtained from $630 \mathrm{~g} /\left(\right.$ week. $\left.\mathrm{m}^{2}\right)$ to $12 \mathrm{~kg} /\left(\right.$ week. $\left.\mathrm{m}^{2}\right)$. These encouraging results could be improved in future by studying more extensively the temperature/humidity pair providing the best yield. In parallel, a numerical model describing mass transfers (before crystallization began) was initiated. The first numerical results correctly reflect experimental observations and encourage further development. 


\section{Acknowledgement}

The authors acknowledge financial support from the French Agence Nationale de la Recherche (ANR) under reference ANR-12-EMMA-0023 (Nano-OxTi project).

\section{References}

[1] Pfaff, G.;Reynders, P. Angle-dependent optical effects deriving from submicron structures of films and pigments. Chemical Reviews 1999, 99(7), 1963-1982.

[2] Zhu, Y.; Shi, J.; Zhang, Z.; Zhang, C., Zhang, X. Development of a gas sensor utilizing chemiluminescence onf nanosized titatnium dioxide. Analytical Chemistry 2002, 74(1), 120-124.

[3] Carp, O.; Huisman, C.L.; Reller, A. Photoinduced reactivity of titanium dioxide. Progess in Solid State Chemistry 2004, 32 (1-2), 33-177.

[4] Liu, C.E.; Rouet, A.; Sutrisno, H.; Puzenat, E.; Terrisse, H.; Brohan, L.; Richard-Plouet, M. Low temperature synthesis of nanocrystallizes titanium oxides with layered of tridimensional frameworks, from $\left[\mathrm{Ti}_{8} \mathrm{O}_{12}\left(\mathrm{H}_{2} \mathrm{O}\right)_{24}\right] \mathrm{Cl}_{8} \cdot \mathrm{HCl} \cdot 7 \mathrm{H}_{2} \mathrm{O}$. Chemistry of Material 2008, 20, 4739-4748.

[5] Brohan, L.; Sutrisno, H.; Puzenat, E.; Rouet, A.; Terrisse, H. French CNRS Patent 0305619, May 9, 2003; International Publication WO 2004/101436 A2, Nov 25, 2004; European CNRS patent (EP) 04742 604.4, Nov 24, 2005; Japan (JP) CNRS Patent 2006-530327, Oct 16, 2006; United States (US) CNRS Patent 018344/0578, Feb 4, 2006.

[6] Perry, R.H.; Green, D.W. Perry's chemical engineers'handbook, McGraw-Hill: New York, 1999. 